\title{
O CONCEITO DE APRENDIZAGEM NA INTERLOCUÇÃO NEUROCIÊNCIA E EDUCAÇÃO EM TESES DOUTORAIS
}

\author{
THE CONCEPT OF LEARNING IN THE DIALOGUE NEUROSCIENCE AND EDUCATION IN \\ DOCTORAL THESES
}

\section{EL CONCEPTO DE APRENDIZAJE EN INTERLOCUCIÓN NEUROCIENCIA Y EDUCACIÓN EN TESIS DOCTORALES}

\section{Iran Abreu Mendes \\ iD 9 \\ Pós-Doutor em Educação \\ Matemática pela Universidade \\ Estadual Paulista/Rio Claro \\ (UNESP) \\ Professor Titular do Instituto de \\ Educação Matemática e Científica \\ (IEMCI) \\ iamendes1@gmail.com}

\section{Valdete Leal de Oliveira (iD) 9}

Doutora em Educação em Ciências e Matemáticas pela Universidade Federal do Pará (UFPA)

Professora do Instituto de

Educação Matemática e Científica (IEMCI)

valdetelealdeoliveira@gmail.br

\begin{abstract}
Resumo
A conexão neurociência e educação objetiva compreender e explicar como nosso cérebro interage para uma aprendizagem sociocognitiva, biológica e cultural, implicando na interação das dimensões biológicas e neurológicas com a dimensão humana, emocional, cognitiva e social. Este artigo discute como a aprendizagem na interlocução neurociência e educação está tratada em teses de doutorado, para identificarmos quais potencialidades dessas produções para repensar a docência na formação e professores. A pesquisa constou de um levantamento bibliográfico seguido da análise dos conteúdos identificados em 13 teses sobre o tema, de modo a verificar interfaces entre neurociência e educação nesses estudos. Nossa conclusão é que as teses indicam a necessidade de avançar nas pesquisas sobre essa interlocução em cursos de formação de professores, visando aproximar esses conhecimentos das pesquisas em Educação em Ciências e Matemática, apontando contribuições que nos desafiam para um aprofundamento investigativo no exercício da docência.
\end{abstract}

Palavras-chave: Educação. Cérebro. Mente. Neurociência. Aprendizagem.

Recebido em: 9 de novembro de 2020.

Aprovado em: 27 de dezembro de 2020.

Como citar esse artigo (ABNT):

MENDES, Iran Abreu; OLIVEIRA, Valdete Leal de. O conceito de aprendizagem na (inter)locução entre neurociência e educação em teses doutorais. Revista Prática Docente, v. 6, n. 1, e003, 2020. 


\begin{abstract}
The connection between neuroscience and education aims to understand and explain how our brain interacts for a sociocognitive, biological and cultural learning, implying the interaction of biological and neurological dimensions with the human, emotional, cognitive and social dimensions. This article discusses how learning in neuroscience and education interlocution is dealt with in doctoral theses, in order to identify what potential of these productions to rethink teaching in training and teachers. The research consisted of a bibliographic survey followed by the analysis of the contents identified in 13 theses on the theme, in order to verify interfaces between neuroscience and education in these studies. Our conclusion is that the theses indicate the need to advance research on this interlocution in teacher training courses, aiming to bring this knowledge closer to research in Science and Mathematics Education, pointing out contributions that challenge us to investigate further in the exercise of teaching.
\end{abstract}

Keywords: Education. Brain. Mind. Neuroscience. Learning.

\title{
Resumen
}

La conexión entre neurociencia y educación tiene como objetivo comprender y explicar cómo nuestro cerebro interactúa para un aprendizaje socio-cognitivo, biológico y cultural, implicando la interacción de las dimensiones biológicas y neurológicas con la dimensión humana, emocional, cognitiva y social. En este artículo se analiza cómo se aborda el aprendizaje en neurociencia y la interlocución de la educación en las tesis doctorales, con el fin de identificar qué potencialidad de estas producciones para repensar la docencia en la formación y el profesorado. La investigación consistió en un levantamiento bibliográfico seguido del análisis de los contenidos identificados en 13 tesis sobre el tema, con el fin de verificar las interfaces entre neurociencia y educación en estos estudios. Nuestra conclusión es que las tesis indican la necesidad de avanzar en la investigación sobre esta interlocución en los cursos de formación del profesorado, con el objetivo de acercar este conocimiento a la investigación en Educación Científica y Matemática, señalando aportes que nos desafían a profundizar en la investigación en el ejercicio de la docencia.

Palabras clave: Educación. Cerebro. Mente. Neurociencia. Aprendizaje. 


\section{INTRODUÇÃO}

Na década de 1960 criou-se a palavra 'Neurociência', que se popularizou com a fundação da primeira sociedade neurocientífica do mundo registrada em 1969, nos Estados Unidos - Washington D.C, cujo objetivo era congregar profissionais com diferentes formações acadêmicas interessados em pesquisar o encéfalo (BEAR, CONNORS \& PARADISO, 2017). Para Kandel, Schwartz e Jessel (1997) o objetivo geral da Neurociência é compreender como o encéfalo nos torna únicos no mundo, a partir de um conjunto de ciências que estudam o sistema nervoso e suas relações com o comportamento (SILVA \& MORINO, 2012), com base em um enfoque interdisciplinar (FERREIRA, GONÇALVES E LAMEIRÃO, 2019). A sua interlocução Neurociência, Educação e a Psicologia veio estabelecer uma nova abordagem para estudos e pesquisas nesse domínio, denominado, então, por Neuroeducação, o qual representa um avanço para os estudos sobre a aprendizagem (GUAPINDAIA, 2019).

Todavia, essa interlocução ainda enfrenta muitos desafios, pois a abordagem por meio da Neuroeducação ainda não faz parte da formação da maioria dos educadores. A esse respeito, Silva e Morino (2012) assinalam que no âmbito educacional há pelo menos duas correntes de pensamento com concepções distintas e opostas quanto às contribuições das Neurociência para a área de formação de professores: 1) uma corrente que apoia essa aproximação e; 2) outra que rejeita essa aproximação.

Diante de tal quadro esse artigo foi elaborado, tomando como base os resultados de uma pesquisa mais ampla sobre esse tema (OLIVEIRA, 2020), a qual evidenciou as Instituições de Ensino Superior, os Programas de Pós-Graduação, Linhas de Pesquisa, Temas, Tipos de Pesquisa e Sujeitos das teses doutorais desenvolvidas no Brasil em Neurociência e outras áreas de conhecimento, com o objetivo de realizar um estudo descritivo-analítico sobre esses trabalhos doutorais durante o período de 2007-2018 , supondo que de posse de informações se poderá delinear encaminhamentos para futuros estudos e pesquisas em prol da melhoria da aprendizagem na formação de professores dos anos iniciais e suas ações na escola.

A pesquisa de Oliveira (2020) partiu das seguintes indagações: O que as teses em Neurociência enfocam sobre aprendizagem? Como tratam desse conceito nos entrelaçamentos de seus problemas de pesquisas e nas discussões estabelecidas? Quais formas de tratar das relações conceituais sobre aprendizagem estão abordadas nessas pesquisas? Que tipo de

\footnotetext{
1 A finalidade foi focalizar como foram discutidas relações sobre aprendizagem na perspectiva conceitual estabelecida pelas Neurociência
} 
contribuições podem apontar para se repensar a aprendizagem na ótica da Neurociência? Como podem implicar para se repensar a aprendizagem? Quais as aproximações e distanciamentos dessas relações conceituais com a abordagem conceitual proposta por Eric Richard Kandell (2014), um dos cientistas que centraram seus estudos sobre essas relações na atualidade?

De outra maneira de anunciar o estudo, nos questionamos se as pesquisas desenvolvidas em Neurociência apresentavam algum tipo de contribuição às pesquisas desenvolvidas no campo da aprendizagem? Para responder a esta questão realizamos uma pesquisa exploratória a fim de identificar como tais aspectos se manifestaram implícita ou explicitamente nessas teses produzidas em Neurociência durante o período delineado (2007-2018), a partir da perspectiva neurocientífica propostas por Kandell et al (2014). Igualmente, a intenção era, ainda, revelar quais concepções de aprendizagem foram mobilizadas nessas produções, caso elas existissem e fossem diferentes das propostas de Kandell.

No presente artigo, além de considerações ancoradas na pesquisa de Oliveira (2020) são apresentadas e analisadas algumas contribuições da Neurociência para a formação dos professores, no que diz respeito à concepção de aprendizagem fundamentada na interlocução Neurociência e Educação.

\section{CONCEPÇÕES DE APRENDIZAGEM: UMA APROXIMAÇÃo COM A NEUROCIÊNCIA}

Na visão de Jean Piaget a aprendizagem ocorre de maneira construtiva, iniciando-se desde os primeiros momentos da vida no curso das interações do ser humano com o meio. As sensações e percepções contribuem para os primeiros "passos" até se alcançar a autonomia. O desenvolvimento da inteligência relaciona-se à adaptação ao meio. A aprendizagem acontece a partir da construção de estruturas de inteligências, as quais possibilitam ao indivíduo conseguir uma adaptação ao mundo real em um processo cada vez mais intenso (PIAGET, 1994).

No entendimento de Corrêa (2017), a concepção de aprendizagem de Piaget está associada à capacidade do ser humano conhecer os objetos, agir sobre eles e transformá-los, atribuindo-lhes significados. "O ser humano conhece, compreende, inventa, cria, constrói e reconstrói” (CORRÊA, 2017, p.381). Um modo de exemplificar como o sujeito faz uma abstração do objeto fica evidente quando uma criança caracteriza um lápis menor que outro, a qualidade "menor que" não está no lápis, mas foi atribuída pelo sujeito.

Saber que o ser humano age sobre os objetos criando significados foi um passo importante no entendimento acerca da aprendizagem, porém, não explica como o cérebro funciona nesse processo, qual a relação entre estímulos e alterações de ordem biológicas com 
reflexos no emocional e cognitivo, questões a serem investigadas para se conhecer tais aspectos do ato de aprender.

Outro expoente do construtivismo foi Vygotsky, o qual elaborou a teoria socioconstrutivista da aprendizagem. Ele, como Piaget, reconheceu a formação de estruturas mentais. Na sua concepção o ser humano aprende por mediação, convivência e partilha até que diversas estruturas sejam internalizadas. Estabeleceu o conceito de zona de desenvolvimento proximal (ZDP), como o espaço-momento em que o papel do outro é crucial na condução da aprendizagem (VYGOTSKY, 2009).

A ZDP concebida por Vygotsky é, portanto, a distância entre o desenvolvimento real de uma criança e o que ela ainda possui de potencial para aprender. Essa "potencialidade" não é maximizada sem a ajuda de um mediador. A ênfase no aspecto social da aprendizagem é notória, mas não se verifica um aprofundamento acerca de como o sistema nervoso (SN) funciona durante o processo de mediação.

Enquanto Piaget considerava que o desenvolvimento das estruturas intelectuais vem antes do aprendizado, para Vygotsky o aprendizado vem primeiro, porque este não se subordina totalmente ao desenvolvimento das estruturas. O correto, na visão de Vygotsky, seria ensinar antecipadamente aquilo que a criança ainda não sabe e nem é capaz de aprender (VYGOTSKY, 2009).

A visão sociointeracionista deixou grandes contribuições para o entendimento do processo de aprendizagem, mas há questões sem resposta que encontram na Neurociência um horizonte ainda não explorado. Por exemplo, Piaget reconheceu o fortalecimento da solidariedade dos adolescentes na escola a tal ponto de levá-los a refletir sem insensatez em determinadas situações (PIAGET, 1994). Porém, as causas associadas ao sistema nervoso desse tipo de comportamento e as relações com o processo de aprendizagem não foram investigadas. Vygotsky considerou a relevância da linguagem na formação do pensamento generalizante, sem, contudo, haver explicações de como o (SNC) funciona em termos de estímulo na aprendizagem da língua, e quais as reações biológicas no contato com diferentes formas de aprender as palavras, dentre outras situações a serem respondidas.

Em Neurociência, quando se fala em aprendizagem refere-se a processos neurais, redes que se estabelecem e neurônios que estabelecem novas sinapses. A aprendizagem é um processo complexo pelo qual o encéfalo reage aos estímulos do ambiente, ativa sinapses, tornando-as mais intensas (BEAR, CONNORS \& PARADISO, 2017; KANDEL et al, 2014; LENT, 2010). 
A cada estímulo novo, a cada repetição de um comportamento que se deseja consolidar, circuitos são acionados e processam as informações que deverão ser, então, consolidadas. $\mathrm{O}$ SNC é ativo no processo de aprender. Suas regiões, lobos, sulcos, reentrâncias desempenham funções e real importância em um trabalho conjunto, onde cada um interage com o outro. Assim através da Neurociência poderemos entender como as redes neurais são estabelecidas no momento da aprendizagem e como os estímulos chegam e saem do SNC, como as memórias se consolidam e como obtemos acesso às informações armazenadas no momento em que precisamos lembrar um evento. A Neurociência chama nossa atenção para os processos biológicos envolvidos na aprendizagem.

A esse respeito as reflexões de Salla (2014) comungam das explicações de Kandel et al (2014), esclarecendo que o SNC sofre modificações em contato com o meio durante toda a vida humana. As experiências vivenciadas no ambiente interferem no SNC e causam alterações anatômicas no cérebro. A quantidade de neurônios e as conexões entre eles (sinapses) são modificadas com as novas experiências. Essa descoberta fortalece a possibilidade de interlocução Neurociência e Educação, pois o próprio Vygotsky afirmou que a interação social possibilita ao ser humano desenvolver funções psicológicas superiores com o tempo.

Entende-se, assim, a possibilidade dos aspectos biológicos, a exemplo da anatomia do cérebro, sofrerem alterações com a participação do ser humano no meio social. Essa descoberta representa uma das primeiras explicações de caráter neurocientífico para importância da zona de desenvolvimento proximal (ZDP) no alcance das potencialidades necessárias às novas aprendizagens, devido sua ligação com a interação social. Porém, os benefícios dessa interatividade não dependem apenas dos aspectos da sociabilidade em si, pois surtem efeitos na estrutura do SNC, restando ampliar pesquisas para entender melhor esse processo.

No âmbito da Neurociência já se descobriu que ambientes ricos contribuem para ampliar as sinapses. Nesse aspecto particular é possível recorrer à Pedagogia para explorar sobre quais estratégias de ensino podem mais adequadamente estimular o aprendizado do estudante (SALLA, 2014). Como afirmava Piaget (1994), não basta ter apenas um meio provocativo e motivador, mas o organismo dos indivíduos precisa estar apto, ser capaz de se sensibilizar com os estímulos oferecidos e reagir a eles. Por isso, a aprendizagem não é igual para todos, difere com os níveis de desenvolvimento de cada um. A construção de determinados conhecimentos também depende certos domínios. 
O fato da aprendizagem não ser igual para todos representa um desafio ainda para compreendê-la no âmbito da interlocução Neurociência e Educação, porque essa "desigualdade" não se limita apenas à interação entre ser humano e contexto ambiental, mas abrange também, a estrutura do SNC, as disfunções e necessidades especiais de cada indivíduo.

Nesse sentido, os estudos de Kandel et al (2014) incrementam novos elementos de análise, esclarecem que a informação visual também contribui na comunicação infantil para aprendizagem da língua, porque influencia a percepção da fala na vida diária. Sendo assim, as categorias da fala são afetadas tanto auditiva, quando visualmente. Portanto, a percepção humana é controlada pela imagem e pelo som, no processo de aprendizagem da linguagem “(...) as crianças precisam descobrir como os sons são agrupados em sua língua para diferenciá-los de maneira significativa" (KANDEL et al, 2014, p. 1.180). No caso das crianças pequenas elas memorizam associando imagens uma a outra. Com o desenvolvimento, a criança passa a memorizar e aprender pela influência também da linguagem, estabelecendo uma relação conceitual. A memória deixa de ser apoiada mais especificamente nos sentidos para ser mais ancorada na própria prática cultural da linguagem (SALLA, 2014).

As “pistas” visuais são de grande relevância no processo de aprendizagem, porque desde as primeiras descobertas da linguagem a criança que possui visão sem deficiência a utiliza para compreender a fala, como evidencia Kandel et al (2014, p. 1.184):

Estudos adicionais indicam que uma informação visual de outro tipo, o rosto falante,
não só é muito útil para a comunicação, mas também influencia a percepção da fala
na vida diária. Todos já devem ter experimentado os benefícios da leitura labial em
festas barulhentas. Observar os movimentos da boca auxilia a compreender a fala em
ambiente ruidoso. A demonstração em laboratório mais convincente de que a visão
desempenha um papel na percepção da fala na vida diária é a ilusão que resulta quando
são enviadas informações visuais discrepantes em relação à fala ouvida. Quando os
sujeitos escutam o som /ba/ enquanto observam uma pessoa pronunciar "ga", eles
relatam ouvir uma articulação intermediária /da/. Tais demonstrações apoiam a ideia
de que as categorias da fala sejam definidas tanto auditiva quanto visualmente e de
que a percepção seja controlada tanto pela imagem quanto pelo som.

As colocações evidenciadas na citação anteriormente exposta, permitem cogitar que os elementos visuais auxiliam o ser humano a aprender a linguagem. Essa constatação fortalece o argumento de que mesmo em anos posteriores do desenvolvimento, o ser humano se beneficia dos meios visuais para aprender. Um exemplo é o ensino da geometria, pois as figuras geométricas encontram-se representadas no cotidiano, e ao serem visualizadas favorecem a memorização das relações (fórmulas) e as utilidades dos cálculos.

Portanto, a memorização é tomada como um fenômeno que desde os primeiros anos de aprendizagem auxilia os bebês a desenvolver a linguagem. Tal fato cognitivo ocorre por meio 
de pistas prosódicas na fala, como tom, duração e mudanças de sonoridade das palavras. $\mathrm{O}$ desenvolvimento desses processos depende da ativação de circuitos ou redes neurais, que ocorre por associações. Uma rede é ativada por outra e assim sucessivamente. Quanto mais frequente essa associação acontece, maior é a probabilidade de se tornar estáveis e fortes as conexões sinápticas estabelecidas, favorecendo a recuperação da memória. A repetição da informação e a associação do novo dado aos conhecimentos já adquiridos favorece a aprendizagem, que se torna consolidada quando o aprendiz consegue criar ativamente vínculos e relações do conteúdo com o que já está armazenado no seu "arquivo", na forma de conhecimentos (KANDEL et al, 2014).

Por esta razão, Oliveira (2015) pontua a necessidade de o professor compreender a relevância do diálogo com os alunos para saber o que eles trazem de conteúdo, conceitos, entendimentos, e a partir desse repertório cognitivo associar novas informações, e se possível utilizar o método da repetição para favorecer a memorização.

A oportunidade de escutar é fundamental para a aprendizagem. Um dos argumentos a favor dessa afirmativa ancora-se no fato das crianças aprenderem a língua escutando, como ressaltam Kandel et al (2014, p. 1.184):

Na realidade, as crianças aprendem a língua por meio de uma análise detalhada e sofisticada da linguagem que escutam, uma análise capaz de revelar padrões de variação da língua natural. O aprendizado desses padrões, por sua vez, altera a percepção para favorecer a língua nativa (...).

Essa tarefa não é tão simples porque o sistema auditivo precisa rastrear as mudanças rápidas ocorridas nos ritmos e frequências da fala. É mais fácil realizar as distinções na linguagem escrita porque ela apresenta espaços entre as palavras, mas na fala não há intervalos acústicos entre as palavras (KANDEL et al, 2014).

A potencialidade das crianças para aprender a linguagem desde seus primeiros anos de vida foi confirmada pelo psicólogo Peter Eimas, no início da década de 1970, ao demonstrar que os bebês são particularmente bons em escutar mudanças acústicas e apresentam a capacidade de distinguir unidades fonéticas dos idiomas existentes no mundo. Identificou que os bebês são capazes de distinguir tais mudanças nas fronteiras entre categorias fonéticas, inclusive em idiomas que nunca tenham experimentado (KANDEL et al, 2014).

Todavia, o desenvolvimento da criança se caracteriza por mudanças nas habilidades associadas à aprendizagem da linguagem. Por exemplo, “(...). Ao final do primeiro ano, as crianças não discriminam mudanças fonéticas que reconheciam bem seis meses antes. Ao 
mesmo tempo, elas tornam-se significativamente mais aptas a escutar distinções fonéticas da língua nativa. (...)" (KANDEL et al, 2014, p.1.184).

\section{Metodologia}

A fundamentação para o desenvolvimento da investigação que originou esse artigo partiu de uma pesquisa bibliográfica, definida por Severino (2018) como aquela realizada a partir do registro disponível em obras representadas por documentos impressos, abrangendo livros, artigos, teses entre outras. Envolveu a investigação em ambiente virtual, a partir da leitura de artigos, teses, revistas, mas, principalmente, com base na tese doutoral intitulada: "Um estudo descritivo-analítico sobre aprendizagem em pesquisas doutorais sobre Neurociência (2007-2018)", de autoria Oliveira (2020), a partir da qual foram analisados resultados encontrados em 13 teses referentes a aprendizagem sob a perspectiva da Neurociência, servindo de ponto de partida para se mostrar como o tema da interlocução Neurociência e Educação vem sendo tratado. O outro material analisado foi Neurociencia y conducta (KANDEL, Eric.; JESSELL, Thomas.; SCHWARTZ, James H., 1997), por meio do qual se identificou um novo olhar sobre a aprendizagem, fundamentado na perspectiva da relação entre Neurociência e Educação.

Além desses materiais, foram explorados artigos científicos, selecionados em periódicos publicados em plataformas eletrônicas na internet, os quais serviram de subsídio na análise do tema, e que requerem aprofundamento acerca do conceito tradicional de aprendizagem empregado pela Pedagogia na formação atual de professores.

Assim, foi realizado um levantamento em pesquisas doutorais desenvolvidas no Brasil durante o período de 2007-2018, no campo da Neurociência e da Educação, sendo que a primeira parte contemplou o intervalo entre 2007 e 2017, mas devido à necessidade de ampliar o estudo, prolongou-se até 2018. Para viabilizar uma análise mais detalhada sobre como o conceito de aprendizagem vem sendo discutido nesses documentos foi necessário restringirmos a análise em apenas 13 trabalhos de pesquisas doutorais (teses), as quais se inserem na temática da interlocução Neurociência e Educação.

\section{Resultados e Discussão: horizontes nas interlocuÇões entre EducaÇão E NEUROCIÊNCIA}

A pesquisa documental mostrou que ainda não existe de fato uma literatura específica que aborde a interlocução Neurociência e Educação. Talvez um dos obstáculos resida nas 
diferenças teóricas e metodológicas, principalmente, porque a Educação é um campo heterogêneo com várias abordagens, e o que tem sido produzido em Neurociência se encontra basicamente na área da Medicina. Todavia, esses estudos apresentam elementos que ajudam a desdobrar reflexões para o campo da aprendizagem.

O estudo realizado identificou que embora muito se fale da interlocução Neurociência e Educação, atualmente ainda se observa, a partir de estudos desenvolvidos em pesquisas doutorais registradas na Capes, a reduzida aproximação entre as referidas áreas, seja no campo das Neurociência, seja no âmbito da Educação, persistindo a dificuldade de intercambiar referenciais teóricos e metodológicos de maneira inter ou transdisciplinar, com enfoque na integração e saberes.

Nas 13 teses pesquisadas, percebeu-se que a possibilidade dos professores em conectar e integrar os conhecimentos da Neurociência com o campo educacional ainda é um desafio. A aproximação entre Neurociência e Educação já é reconhecida, porém, não contemplada como uma interface aprendizagem versus funcionamento do SNC durante o ato de ensinar e aprender. A base continua sendo o Construtivismo, sem a interatividade efetiva entre ciências biológicas e humanas no que diz respeito aos seus impactos no processo de aprendizagem. Porém, os estudos apontados no quadro 1 deixam evidente o quanto é promissora a temática, porque muitos questionamentos podem ser identificados para o desenvolvimento de novas pesquisas sobre o assunto.

Quadro 1 - Autor(a), o título da tese, ano, nível acadêmico e IES

\begin{tabular}{|c|c|c|c|c|c|}
\hline $\mathbf{N}^{\mathbf{o}}$ & Autor & Título & Ano & Doutorado & IES \\
\hline 01 & $\begin{array}{c}\text { Cristiane } \\
\text { Gonçalves Ribas }\end{array}$ & $\begin{array}{c}\text { Conhecimento e ação da fisioterapia na } \\
\text { escola: contribuições para a formação de } \\
\text { professores de alunos com paralisia } \\
\text { cerebral }\end{array}$ & 2018 & Educação & PUC-PR \\
\hline 02 & $\begin{array}{c}\text { Janete Schmidt de } \\
\text { Camargo Cesar }\end{array}$ & $\begin{array}{c}\text { Memória de Trabalho, estágio de } \\
\text { desenvolvimento intelectual e desempenho } \\
\text { de alunos de } 5^{\circ} \text { ano na Prova Brasil }\end{array}$ & 2018 & Educação & UNICAMP \\
\hline 03 & $\begin{array}{l}\text { Tamara Regina } \\
\text { Reis Sales }\end{array}$ & $\begin{array}{l}\text { Educação, Discalculia e Neurociência: um } \\
\text { estudo de caso em Sergipe }\end{array}$ & 2017 & Educação & $\begin{array}{c}\text { Universidade } \\
\text { Tiradentes }\end{array}$ \\
\hline 04 & $\begin{array}{l}\text { Lyana Virginia } \\
\text { Thediga de } \\
\text { Miranda }\end{array}$ & $\begin{array}{l}\text { Saberes de ação, interação e comunicação: } \\
\text { metodologia ativa e resolução colaborativa } \\
\text { de problemas com crianças na escola }\end{array}$ & 2016 & Educação & UFSC \\
\hline 05 & $\begin{array}{l}\text { Jonathan } \\
\text { Henriques do } \\
\text { Amaral }\end{array}$ & $\begin{array}{c}\text { “A Educação no ‘século do cérebro’: uma } \\
\text { análise de interlocuções entre } \\
\text { Neurociência e a Educação a partir dos } \\
\text { estudos da ciência”" }\end{array}$ & 2016 & Educação & UFRGS \\
\hline 06 & $\begin{array}{l}\text { Sandra Regina } \\
\text { Dias da Costa }\end{array}$ & $\begin{array}{l}\text { Diálogo entre Neurociência e a perspectiva } \\
\text { histórico-cultural: as funções executivas na } \\
\text { educação infantil }\end{array}$ & 2015 & Educação & UNICAMP \\
\hline
\end{tabular}




\begin{tabular}{|c|c|c|c|c|c|}
\hline 07 & $\begin{array}{c}\text { Miliane Nogueira } \\
\text { Magalhães } \\
\text { Benício }\end{array}$ & $\begin{array}{c}\text { A construção da escrita na alfabetização de } \\
\text { jovens e adultos }\end{array}$ & 2015 & Educação & UnB \\
\hline 08 & $\begin{array}{c}\text { Ireuda da Costa } \\
\text { Mourão }\end{array}$ & $\begin{array}{c}\text { Ensino de didática na licenciatura em } \\
\text { química no Brasil }\end{array}$ & 2015 & Educação & UFAM \\
\hline 10 & $\begin{array}{c}\text { Malba Cunha } \\
\text { Tormin }\end{array}$ & $\begin{array}{c}\text { Dubabi Du: uma proposta de formação e } \\
\text { intervenção musical na creche }\end{array}$ & 2014 & Educação & USP \\
\hline 11 & $\begin{array}{c}\text { Letícia Pontes } \\
\text { Rodrigues } \\
\text { Furtado }\end{array}$ & $\begin{array}{c}\text { Aprender um estudo com professores do } \\
\text { curso de graduação em enfermagem de } \\
\text { uma universidade pública }\end{array}$ & 2013 & Educação & UFMT \\
\hline 12 & $\begin{array}{c}\text { Ana majestade o autista: fascínio, } \\
\text { Antolerância e a exclusão no mundo } \\
\text { contemporâneo }\end{array}$ & 2011 & Educação & UFC \\
\hline 13 & $\begin{array}{c}\text { Lenise Henz } \\
\text { Caçula Pistóia }\end{array}$ & $\begin{array}{c}\text { Ensaio sobre o desenvolvimento humano: } \\
\text { jogo e expressividade }\end{array}$ & 2010 & Educação & UFSC \\
\hline
\end{tabular}

Fonte: Oliveira (2020).

Diante desses fatos, são analisados nessa seção os resultados identificados no estudo referente às 13 teses citadas no quadro 1, buscando assim destacar possíveis aproximações entre Neurociência e Educação que possam subsidiar a formação de professores para o entendimento da aprendizagem em uma perspectiva mais ampla, que admita a interação biológico, o psicológico e o social. Portanto, ao nos debruçarmos sobre essas teses buscamos identificar como as perspectivas teóricas de Kandel et al (2014) se faziam presentes nessas pesquisas enquanto fundamentação teórico-epistemológica. Igualmente, procuramos evidenciar como essa área vem se delineando no Brasil.

Assim, destacamos que a tese de Amaral (2016), que analisou 93 produções acadêmicas com a finalidade de discorrer sobre a constituição desse novo campo e os estilos de pensamentos que emergem desta interlocução, elucidou uma questão importante: atualmente a interlocução Neurociência e Educação se mostra como uma temática em processo de apropriação pelo campo de pesquisa educacional, que ainda avançou pouco na relação interdisciplinar ou transdisciplinar, o que se constitui um desafio para a superação das dificuldades na realização e interpretação de estudos empíricos que conjuguem teorias e metodologias que integrem as duas áreas - Neurociência e Educação.

O problema relativo ao emprego de teorias tradicionais no campo educacional é percebível na tese de Miranda (2016), na qual articulou saberes de ação, interação e comunicação à metodologia ativa e resolução colaborativa de problemas com crianças na escola, com a finalidade de investigar se as metodologias ativas podem qualificar e mobilizar competências comunicativas entre crianças de duas turmas do $6^{\circ}$ ano de duas escolas públicas 
de Santa Catarina a partir da RCP. Todavia, não se encontra neste estudo a efetiva interlocução Neurociência e Educação, em que a aprendizagem seja focada a partir das distintas dimensões do ser humano, inclusive, associadas ao SNC.

Outra tese que tratou a aprendizagem centrada no Construtivismo, sem apresentar inovações nesse campo de pesquisa entre Neurociência e Educação foi a elaborada por Mourão (2015), na qual questionou como se configura a didática, quando opera na Formação de Professores de Química em diferentes regiões do Brasil, e o que esta considera como condição de seu ensino? Portanto, focou na formação de professores, mas utilizando de um referencial baseado nas teorias pedagógicas tradicionais.

A tese elaborada por Pontes (2013) se concentrou em estudar a empatia enquanto suporte para as relações estabelecidas entre professor-aluno. A partir de uma abordagem qualitativa e estudo de caso, empregou como instrumentos de coleta de informações a entrevista semiestruturada e o questionário eletrônico. Todavia, o estudo não envolveu o entendimento da aprendizagem associado à interlocução Neurociência e Educação, mediante um "olhar" mais amplo da interdisciplinaridade. Sendo assim, os resultados desta pesquisa demonstraram que professores empáticos contemplam os componentes cognitivos, afetivos e comportamentais de seus alunos, evidenciando a necessidade de aprimoramento de habilidades empáticas por parte do professor para que a aprendizagem ocorra.

Furtado (2011), desenvolveu um estudo bibliográfico com a finalidade de investigar o sentido do fascínio pelo autismo nas suas determinações fantásticas e ideológicas, desmistificando a ideia errônea sobre o autismo que tem "apagado" a subjetividade dos autistas. Embora que seus achados de pesquisa sugerem a existência de diferenças entre as concepções de autismo para a psicanálise e para a Neurociência, não encontramos nesse estudo evidências de uma aproximação efetiva entre Neurociência e Educação, em que a aprendizagem seja focalizada abordando as relações com o SNC.

Nessa mesma linha de abordagem verificamos a tese de Tormin (2014), que analisou a interface da Psicologia, Educação e Música, investigando como as professoras de creche utilizam a linguagem musical junto a bebês com o objetivo de saber se essas ações geravam aprendizado e desenvolvimento musical infantil. A base teórica se fundamentou em Vygotsky, Feuerstein, Bruner e Gordon, além das contribuições de estudos das áreas da Psicologia Cognitiva Musical e Neurociência. Todavia, não se verificou a interlocução Neurociência e 
Educação, de modo a dar conta de uma concepção mais ampla de aprendizagem, na qual se possa verificar as interações do ato de aprender com o SNC e os aspectos biológicos envolvidos.

A tese de Benicio (2015) teve por objetivo analisar o processo de apropriação da escrita, buscando identificar e descrever dois aspectos: 1) que conhecimentos letrados e linguísticos da escrita em português jovens e adultos trazem para escola; 2) que estratégias são construídas pelo estudante que aprende a escrever. A abordagem utilizada foi à qualitativa de cunho etnográfico. Os resultados indicaram que os jovens construíram conhecimentos sobre uma variedade de gênero textual. Nesse estudo também não se verificou a interlocução Neurociência e Educação em uma perspectiva que contempla as distintas dimensões do ser humano, inclusive, associadas ao SNC.

A tese desenvolvida por Pistóia (2009) intitulada Gregory Bateson e a Educação: possíveis entrelaçamentos, objetivou apresentar e discutir as reflexões acerca dos nexos entre Educação como área de conhecimento e a epistemologia desenvolvida por Gregory Bateson, denominada ecologia da mente. Discorre sobre o processo de religação dos saberes, dentre eles os envolvidos na aprendizagem, comunicação humana, estudos da mente, Neurociência e Ciências Cognitivas. A autora defende o pensamento sistêmico imbricado na tríade contextoprocesso-relações nas quais os seres vivos se envolvem constantemente. Tem relevância em elucidar a superação do pensamento cartesiano pelo paradigma transdisciplinar, fundamental no estreitamento das relações entre Educação e Neurociência. Todavia, não aprofunda uma associação entre aprendizagem e o SNC, priorizando a abordagem epistemológica do tema.

Em sua tese Zimmermann (2010), ao partir do questionamento central: "O que a experiência do 'se movimentar' humano, mais especificamente o movimento artístico e esportivo, pode ensinar sobre nós mesmos?", desenvolveu o estudo denominado "Ensaio sobre o movimento humano: jogo e expressividade", no qual recorre aos gestos artísticos e esportivos, para refletir como os indivíduos se constroem no mundo e nas interações sociais estabelecidas. A autora nas concepções fenomenológicas de Merleau-Ponty, discorrendo sobre questões da corporeidade, alma, corpo-vivido, e apresenta discussões sobre as reações do "sistema de neurônios espelho" pela visão, fala, audição, evidenciando que esse sistema é um intérprete ativo da ação, ao invés de um receptor passivo de informações sensoriais. Portanto, sua abordagem traz informações relevantes para uma visão de aprendizagem mais próxima das Neurociência e que podem ser associadas aos conhecimentos no campo da Educação, ampliando o entendimento de seu significado. 
A tese desenvolvida por Sales (2017), intitulada "Educação, discalculia e neurociência: um estudo de caso em Sergipe" com a finalidade de compreender como a Neurociência Educacional pode contribuir no atendimento de pessoas com discalculia focou na aprendizagem, utilizou conceitos como neuroplasticidade, a Teoria das Inteligências Múltiplas, considerou os estágios do desenvolvimento humano, mas não aprofundou a questão do funcionamento do SNC nos momentos de aprendizagem dos sujeitos com discalculia.

A tese elaborada por Costa (2015) também se orientou pelo viés tradicional da relação Educação e Neurociência. Investigou o desenvolvimento do controle inibitório e do autocontrole, a partir do olhar para a prática pedagógica cotidiana da Educação Infantil, sob a perspectiva histórico-cultural. Realizou um estudo empírico orientado pela abordagem histórico-cultural, abordagem qualitativa, de caráter descritivo-participativo, adotando como metodologia a análise de processos interativos ocorridos no cotidiano da sala de aula; seguindo os pressupostos da Psicologia histórico-cultural, sem focar a aprendizagem considerando a associação com o SNC.

A tese de Ribas (2018) buscou aplicar os conhecimentos de ação da fisioterapia aos fundamentos de um programa de formação continuada para professores que atuam na educação infantil modalidade especial com alunos que tem paralisia cerebral (PC), bem como buscou refletir acerca da importância do fisioterapeuta em uma equipe multidisciplinar. Portanto, a ênfase foi na formação e não na aprendizagem. Ademais, não se verificou nessa tese a preocupação em refletir como o SNC funciona no ato de aprender dessas crianças especiais.

Outra tese que centrou seu foco na formação dos professores foi elaborada por Cesar (2018), que investigou a existência da correlação entre memória de trabalho e inteligência no desempenho das crianças do $5^{\circ}$ ano do ensino fundamental na Prova Brasil. Para avaliar a memória de trabalho a autora recorreu ao método clínico desenvolvido por Jean Piaget e aos estudos relacionados à Neurociência. Para a avaliação da memória e da inteligência foi utilizado o método clínico crítico desenvolvido por Jean Piaget, cujas características permitem diagnosticar o estágio de evolução de determinados conceitos, tendo como instrumentos as provas piagetianas das Relações entre Superfícies e Perímetros e A Formação de Correlatos, e o jogo Torre de Hánoi. Todavia, esse estudo mantém a linha de usar a interlocução Neurociência e Educação na perspectiva do Construtivismo. 


\section{A gUISA DE UMA REFLEX̃̃o INTERPRETATIVA}

Após a leitura e análise das teses, fizemos uma correlação entre os resultados extraídos de cada trabalho, com base no referencial teórico adotado. Assim, o estudo das 13 teses demonstrou a necessidade de avançar nas interlocuções entre Neurociência e Educação com vistas a estabelecer uma concepção de aprendizagem que contemple o desenvolvimento integral do ser humano na perspectiva defendida por Bear, Connors e Paradiso (2017), Kandel et al (2014) e Lent (2010). Para esses estudiosos a aprendizagem depende de uma combinação de fatores filogenéticos, ontogenéticos e histórico-culturais, os quais viabilizam a produção da linguagem, do pensamento, dos processos de tomada de decisões, das emoções, dentre outras funções cognitivas próprias dos seres humanos.

Portanto, é imprescindível que os professores adquiram em seus cursos de formação, uma base de conhecimentos acerca dos modos como se originam e se fortalecem as funções em nível encefálico, para então, planejarem como operacionalizar intervenções potencializadoras de aprendizagem.

A Pedagogia já oferece informações relevantes, como a constatação de que a repetição favorece a aprendizagem. Piaget (1994), conforme já comentamos anteriormente, considerou a acomodação como o momento em que o indivíduo se adapta aos objetos reais, ocorrendo modificações em sua estrutura inteligível. Todavia, a maioria dos cursos de formação dos professores não explica como essa reorganização do conhecimento acontece no cérebro. A Neurociência supre essa "lacuna", e evidencia que o SNC possui a capacidade de promover essa reorganização ou readaptação diante de novos estímulos, a qual é denominada de neuroplasticidade (CRUZ, 2016).

Ao compreender como a neuroplasticidade possibilita a reorganização das estruturas do SNC, o professor pode selecionar recursos de ensino multissensoriais, porque estes ativam as múltiplas redes neurais que estabelecem associação entre si. Já se sabe que atividades envolvendo repetição de informações e experiências favorecem a neuroplasticidade e produzem sinapses mais consolidadas (CRUZ, 2016). Todavia, outros fatores podem ser descobertos na interlocução Neurociência e Educação, particularmente, com o desenvolvimento de novas pesquisas com esse objetivo e contribuir para entender a aprendizagem de maneira mais ampla.

O professor também pode ter acesso a informações variadas no âmbito da Neurociência para subsidiar sua prática docente e favorecer a aprendizagem. Um exemplo é compreender que a aprendizagem não está em função apenas de neurônios em redes neurais, mas de vários 
fatores, inclusive, de um SNC saudável, o qual depende de sono regular, atividades físicas, boa alimentação, manter a mente exercitada, entre outros (CRUZ, 2016). Articular esse conhecimento com as necessidades especiais de determinados alunos é uma estratégia relevante para a aprendizagem ainda a ser explorada nos cursos de formação de professores.

A Neurociência explica que os neurônios apresentam regiões celulares distintas, que juntas são responsáveis pela entrada, integração, condução e saída de informações no Sistema Nervoso. Nesse particular há um campo imenso de pesquisas para se identificar como essas regiões reagem ao processo de interação do sujeito com a cultura e com o professor. Vygotsky (2009) explicou que o ser humano aprende por meio da mediação, mas não se sabe até o momento como o SNC reage durante essa experiência. O conhecimento dessas reações, que também envolve as reações biológicas produzidas pelo contato com o contexto ambiental, podem servir de base para se identificar os estímulos de aprendizagem.

A identificação dos estímulos de aprendizagem "vem ao encontro" dos resultados de algumas das 13 teses pesquisadas: a importância da empatia na mediação entre professor e alunos. A empatia refere-se à capacidade do ser humano de colocar-se no lugar do outro. Kandel et al (2014) apresenta uma explicação que vai além de reconhecer a relevância da empatia nessa relação professor/aluno. Segundo o estudioso, a emoção afeta positivamente a região responsável pelos centros de prazer, originando a produção de uma substância denominada de dopamina. Quando ativados tais centros propiciam bem-estar mobilizando a atenção do indivíduo e reforçando o comportamento em relação ao objeto do afeto.

O entendimento dos efeitos da empatia nos centros de prazer do cérebro é um novo olhar acerca da aprendizagem, viabilizado pela interlocução Neurociência e Educação. A maioria dos professores não sabe desse efeito. Ter acesso a essa informação representa um grande avanço para sensibilizar e estimular os educadores a dar mais importância ao diálogo, uma das questões bastante discutidas pela Pedagogia. A interação com os alunos, a necessidade de se colocar no lugar do outro, é um dos assuntos abordados por algumas das 13 teses.

Esses resultados corroboram para confirmar o posicionamento de Silva (2016), quando defende que as salas de aula devem se transformar em contextos agradáveis, onde as informações trabalhadas pelo professor possam ser melhor assimiladas pelos alunos, e a aprendizagem se constitua em evento prazeroso. Essa visão já se encontra no cerne da abordagem interacionista do Construtivismo, a qual concebe a aprendizagem significativa como 
aquela estimulada pelo prazer e pela curiosidade, reconhecendo o professor na condição de mediador e o aluno no papel de agente ativo no processo de construção de seu conhecimento.

Todavia, os professores não trabalham apenas com crianças sadias ou isentas de necessidades especiais. Entre as 13 teses é possível encontrar referência ao caso da paralisia cerebral. Nesse particular, a interlocução Neurociência e Educação necessita se aprofundar mais sobre as afasias clássicas. Kandel et al (2014) demonstram que a Neurociência pode ajudar os professores a compreender o funcionamento das anomalias no SNC as motivações a serem adotadas no processo de aprendizagem. Um dos horizontes promissores é o conhecimento produzido pela Neuropsicologia, área de estudos que correlaciona as funções cognitivas ao comportamento e a atividade do sistema nervoso em condições normais e disfuncionais. Esta tem contribuído para a compreensão de transtornos de déficit de atenção/hiperatividade.

É oportuno ressaltar que os professores encontram fragilidade na formação para lidar com os alunos público-alvo da Educação Especial. Promover a autonomia de alunos com Transtornos de Déficit de Atenção/Hiperatividade (TDAH) e outras Necessidades Educacionais Especiais (NEE) demanda conhecimentos específicos, inclusive, no âmbito da Neurociência. Tavares; Santos e Freitas (2016, p.2) esclarecem: “(...) os cursos de formação docente têm enfatizado aspectos teóricos, distantes da prática pedagógica, não preparando os profissionais para lidar com a diversidade dos educandos". Uma das falhas nessa formação é a não interlocução Neurociência e Educação, pois a TDAH é um transtorno neuropsiquiátrico. Não basta apenas saber seus sintomas, características, possíveis causas, é preciso compreender como o SNC funciona no momento do ensino e da aprendizagem. Silva e Mello (2018) evidenciam que o trabalho do educador se torna mais significativo e eficiente quando passa a conhecer esse funcionamento.

Umas das contribuições acerca da compreensão do cérebro humano na aprendizagem é a informação que o tom de voz de outras pessoas causa uma reação no SNC, um julgamento como algo ameaçador ou não ameaçador (SILVA; MELLO, 2018). Para melhor entendimento, recorre-se ao conceito de atenção, partindo da função do córtex pré-frontal, que regula três processos básicos: a aquisição de informações por meio de estímulos sensoriais, o processo dessa informação no SNC e a resposta ao estímulo inicial que é devolvida ao meio (BROWN; DIAS, 2017).

O SNC ao interagir com o meio absorve a cada momento novas informações, recebe diversos estímulos sensoriais advindos de diversos canais sensoriais. Um mesmo canal pode 
produzir vários estímulos. Brow e Dias (2017) explicam que a transdução é o processo pelo qual os estímulos sensoriais são transformados em estímulos elétricos. O cérebro seleciona os estímulos conforme algum objetivo, conforme a intensidade de estímulos e com base em experiências vivenciadas. No âmbito da Pedagogia, essa importância do vivenciar experiências tem fundamento em Vygotsky (2009), para o qual a aprendizagem depende da mediação, ou seja, da apropriação dos conhecimentos construídos historicamente por parte do indivíduo, no decorrer de sua vivência, na interatividade com a sociedade e a cultura.

A atenção é uma das funções psicológicas superiores, outras são a memória, a abstração, o comportamento intencional. Brown e Dias (2017) esclarecem que a atenção constitui o processo cognitivo pelo qual o cérebro focaliza e seleciona estímulos. Por meio dela o indivíduo desenvolve a capacidade de percepção da figura fundo. A figura é onde se focaliza a atenção, a visualização ou a audição, o fundo é o contexto onde se encontra o objeto focalizado. No campo visual, um exemplo é focar letras e palavras de um texto. Já o campo auditivo, prestar atenção na voz de uma pessoa com quem se mantém um diálogo em detrimento dos sons do ambiente.

O professor necessita compreender que depois de captadas pelos alunos, as informações precisam ser processadas, isto é, compreendidas, categorizadas, agrupadas e correlacionadas com as demais informações resgatadas pela memória (BROWN; DIAS, 2017). Essas explicações se relacionam com as três noções de Piaget (1994) sobre a aprendizagem: Esquema, Assimilação e Acomodação. O Esquema são as estruturas mentais referentes a um todo organizado. Assimilação é a capacidade de um sujeito incorporar objetos da cognição à sua estrutura cognitiva já existente, correspondendo à correlação com as informações resgatadas pela memória. Acomodação é o reajuste na estrutura de modo a incorporar um novo objeto do conhecimento.

Todavia, quando se trata de um indivíduo com TDAH o processamento das informações é mais dificultoso devido ao déficit de atenção decorrente do funcionamento alterado no sistema neurobiológico cerebral. Os neurotransmissores encontram-se em quantidade ou qualidade alterada. O córtex pré-frontal não cumpre o papel de selecionar apenas as informações necessárias para a aprendizagem, pois todas as informações entram simultaneamente. O cérebro sofre uma sobrecarga de estímulos e informações vindas dos sentidos, dificultando o foco da atenção. Nesse caso, capacidade “(...) visualizar ou distinguir sonoramente a figura fundo se torna um desafio" (BROWN; DIAS, 2017, p.5). 
Portanto, é preciso superar a lógica cartesiana na formação dos professores, substituindo-a pelo viés da interdisciplinaridade e da transdisciplinaridade, pois assim será possível ao educador compreender a aprendizagem em sua amplitude, como um processo cujas particularidades contemplam também os conhecimentos da Neurociência.

\section{CONSIDERAÇÕES FINAIS}

O assunto abordado neste artigo permitiu compreender a relevância de aproximar Educação e Neurociência com a finalidade de entender o processo de aprendizagem em uma perspectiva diferente do que ainda prevalece, limitada aos princípios construtivistas relativamente à perspectiva individual.

Nossas reflexões apontam que a interlocução Neurociência e Educação se mostra possível, mas seu avanço exige incentivo à pesquisa e à extensão. Conforme identificado a partir do estudo da literatura específica em artigos, livros e pesquisas doutorais produzidas no Brasil (2007-2018), constatamos que os avanços no campo da Neurociência datam das décadas de 1970 e 1980. Porém, a aproximação deste campo com a Educação e a área de formação de professores não se efetivou na mesma proporção, dificultando aos profissionais que atuam nesses campos compreender como ocorre o funcionamento do cérebro durante o processo de aprendizagem.

O estudo realizado mostra que é notória a contribuição da Neurociência para o campo da Educação, particularmente no âmbito da aprendizagem, decorrente dos estudos realizados nas últimas décadas do século XX e as primeiras do século XXI, considerando, ainda, o desenvolvimento das tecnologias de imagem, pois estes representam um avanço no processo de aquisição, processamento e consolidação da informação em nível cortical, consequentemente, acrescentando achados relevantes à compreensão dos processos de aprendizagem. Neste sentido, uma das contribuições da Neurociência, de destaque no campo da aprendizagem, diz respeito às evidências de que no momento da aprendizagem ocorrem várias modificações em nível encefálico quando se originam e fortalecem sinapses, redes e circuitos neurais.

Como a aprendizagem é um processo composto pela combinação de fatores filogenéticos, ontogenéticos e histórico-culturais que fazem parte do desenvolvimento humano, produzindo a linguagem, o pensamento, os processos de tomadas de decisões, as emoções, dentre outras funções cognitivas expressas pelo desenvolvimento dos seres humanos, sua complexidade é ampla. Portanto, se torna precisamente necessária à sua exploração por meio de interlocuções estabelecidas em pesquisas que envolvam a Educação e as Neurociência, a fim 
de reconhecer que o cérebro e o sistema nervoso operam reagindo a diferentes estímulos, e essa reação é concomitantemente acompanhada de uma aprendizagem.

Lamentavelmente, ainda são escassas as pesquisas doutorais produzidas articuladamente envolvendo conexões de campos científicos como a psicologia, educação, ensino de ciências e matemática, dentre outros que visem elucidar as possíveis implicações da Neurociência (BEAR, CONNORS \& PARADISO, 2017; KANDEL et al, 2014) para o desenvolvimento de expertises sobre formas de aprendizagem nesses campos. Nessa falta de encaminhamentos investigativos e de resultados socializados, acaba por prevalecer o domínio das perspectivas médicas e psicológicas no âmbito dessas investigações científicas e de aplicações de seus resultados para explicar os processos de aprendizagem.

Ainda com relação às pesquisas desenvolvidas na interlocução Neurociência e Educação, os resultados identificados nos fizeram refletir que tais investigações geralmente discutem temas como autismo, discalculia, relação professor-aluno, comunicação e interação assertiva em ambientes de sala de aula, corpo e expressividade, e temas similares. Todavia, o estudo das 13 pesquisas doutorais evidenciou os esforços para realizar aproximações adequadas e possíveis entrelaçamentos de temas, para solucionar problemas que envolvem interrogações a serem ser respondidas por ambas as áreas, visando compreender como a aprendizagem ocorre em nível encefálico. Assim é possível afiançar que atualmente estas preocupações passaram a ocupar lugar de destaque em agendas de estudos e pesquisas que estão sendo feitos pelos profissionais de Educação.

\section{REFERÊNCIAS}

AMARAL, Jonathan Henriques do. A Educação no 'século do cérebro': análise de interlocuções entre Neurociência e Educação a partir dos Estudos da Ciência". 2016. Tese (Doutorado em Educação). Faculdade de Educação, Universidade Federal do Rio Grande do Sul. Porto Alegre, 2016.

BEAR, Mark F.; CONNORS, Barry W.; PARADISO, Michael A. Neurociência: desvendando o sistema nervoso. 4. ed. Porto Alegre: Artmed. 2017.

BENICIO, Miliane Nogueira Magalhães. A construção da escrita na alfabetização de jovens e adultos. 2015. Tese (Doutorado em Educação). Faculdade de Educação, Universidade de Brasília, Brasília 2015.

BROWN, Denise; DIAS, Fabiana. Compreendendo e ajudando alunos com déficit de atenção: buscando novas estratégias pedagógicas. 2017. Disponível: https://www.cp2.g12.br/ojs/index.php/anosiniciais/article/view/1113/814. Acesso em: 11 out. 2020. 
CESAR, Janete Schmidt de Camargo: Memória de trabalho, estágio de desenvolvimento intelectual e desempenho de alunos de $5^{\circ}$ ano na Prova Brasil. 2018. Tese (Doutorado em Educação). Faculdade de Educação, Universidade Estadual de Campinas, Campinas, 2018.

CORRÊA, Crístia Rosineiri Gonçalves Lopes. A relação entre desenvolvimento humano e aprendizagem: perspectivas teóricas. Psicologia Escolar e Educacional, v. 21, n. 3, p. 379386, 2017. ISSN 2175-3539. Disponível em: https://www.scielo.br/pdf/pee/v21n3/2175-3539pee-21-03-379.pdf. Acesso em: 11 set. 2020. DOI: 10.1590/2175-3539201702131117.

COSTA, Sandra Regina Dias da. Diálogo entre Neurociência e a perspectiva históricocultural: as funções executivas na educação infantil. 2015. Tese (Doutorado em Educação). Faculdade de Educação, Universidade Estadual de Campinas, Campinas, 2015.

CRUZ, Luciana Hoffert. C. Bases neuroanatômicas e neurofisiológicas do processo ensino e aprendizagem. 2016. In: III Curso de Atualização de Professores de Educação Infantil, Ensino Fundamental e Médio - A Neurociência e a Educação: como nosso cérebro aprende? Disponível em: https://www.repositorio.ufop.br. Acesso em: 26 out. 2020.

FERREIRA, Hercio da Silva.; GONÇALVES, Tadeu Oliver.; LAMEIRÃO, Soraia Valéria de Oliveira Coelho. Aproximações entre Neurociência e educação: uma revisão sistemática. Revista Exitus. Santarém, PA, vol. 9, n. 3. p. 636 - 662. 2019.

FURTADO, Luis Achilles Rodrigues. Sua majestade o autista: fascínio, intolerância e exclusão no mundo contemporâneo. 2011. Tese (Doutorado em Educação). Faculdade de Educação, Universidade Federal do Ceará, Fortaleza, 2011.

GUAPINDAIA, Liliane Teles. A Psicomotricidade como facilitadora no processo de Ensino e Aprendizagem na Educação Infantil. 2019. Disponível em:

https://psicologado.com.br/psicologia-geral/desenvolvimento-humano/a-psicomotricidadecomo-facilitadora-no-processo-de-ensino-e-aprendizagem-na-educacao-infantil. Acesso em: 28 ago. 2020.

KANDEL, Eric.; JESSELL, Thomas.; SCHWARTZ, James H. Neurociencia y conducta. Madrid: Prentice Hall, 1997.

LENT, Roberto: Cem Bilhões de Neurônios? Conceitos fundamentais de Neurociência. 2. ed. São Paulo: Editora Atheneu. 2010.

MIRANDA, Lyana Virginia Thediga de. Saberes de ação, interação e comunicação: metodologia ativa e resolução colaborativa de problemas com crianças na escola. 2016. Tese (Doutorado em Educação). Faculdade de Educação, Universidade Federal de Santa Catarina, 2016.

MOURÃO, Ireuda da Costa. Ensino de didática na licenciatura em Química no Brasil Manaus-AM. 2015.Tese (Doutorado em Educação). Faculdade de Educação, Universidade Federal do Amazonas, Manaus, 2015.

OLIVEIRA, Nanci de. Linguagem, comunicação e matemática. Revista de Educação, v. 10, n. 10, 2015. Disponível em: 
https://revista.pgsskroton.com/index.php/educ/article/viewFile/2146/2043. Acesso_em: 21 jan. 2020.

PIAGET, Jean. O Juízo Moral na Criança. São Paulo: Summus, 1994.

PISTÓIA, Lenise Henz C. Gregory Bateson e a Educação: possíveis entrelaçamentos. 2009. Tese (Doutorado em Educação). Faculdade de Educação, Universidade Federal do Rio Grande do Sul, Porto Alegre, 2009.

PONTES, Leticia. A empatia no processo de ensinar e aprender: um estudo com professores do curso de graduação em Enfermagem de uma universidade pública. 2013. Tese (Doutorado em Educação). Faculdade de Educação, Universidade Federal de Mato Grosso, Cuiabá, 2013.

RIBAS, Cristiane Goncalves. Conhecimento e ação da fisioterapia na escola: contribuições para a formação de professores de alunos com paralisia cerebral. 2018. Tese (Doutorado em Educação). Pontifícia Universidade Católica do Paraná, Curitiba, 2018.

SALLA, Fernanda. Neurociência: como ela ajuda a entender a aprendizagem. São Paulo: Cortez, 2014.

SEVERINO, Antônio Joaquim. Metodologia do trabalho científico. São Paulo: Cortez, 2018.

SILVA, Fiderisa da.; MORINO, Carlos Richard Ibañez. A importância das Neurociência na formação de professores. Momento. Diálogos em Educação. Rio Grande, RS, vol. 21, n. 1.p. 29-50, 2012.

SILVA, Luciane Grecilo; MELLO, Elena Maria Billig. Fundamentos de neurociência presentes na Inclusão Escolar: vivências docentes. Revista Educação Especial. v. 31, n. 62, jul./set. 2018. Disponível em:

https://periodicos.ufsm.br/educacaoespecial/article/view/28388/pdf. Acesso em: 10 out. 2020.

TAVARES, Lídia Mara Fernandes Lopes; SANTOS, Larissa Medeiros Marinho dos.; FREITAS, Maria Nivalda Carvalho. A Educação Inclusiva: um Estudo sobre a Formação Docente. Revista Brasileira de Educação Especial. V. 22, n. 4, p. 527-542, 2016. ISSN 1980-5470. Disponível em: https://www.scielo.br/scielo.php?script=sci_arttext\&pid=S141365382016000400527. Acesso em: 07 out. 2020. 10.1590/s1413-65382216000400005.

TORMIN, Malba Cunha. Dubabi Du: uma proposta de formação e intervenção musical na creche. 2014. Tese (Doutorado em Educação). Faculdade de Educação, Universidade de São Paulo, São Paulo, 2014.

VYGOTSKY, Lev S. A construção do pensamento e da linguagem. São Paulo: WMF, 2009.

ZIMMERMANN, Ana Cristina. Ensaio sobre o movimento humano: jogo e expressividade. 2010. Tese (Doutorado em educação). Centro de Ciências da Educação. Universidade Federal de Santa Catarina, Florianópolis, 2010. 